\title{
Effects of Capillary Shape on Flow Characteristics and Degradation of Polymer Solutions
}

\author{
Hobart S. White and Harriet V. Belcher
}

\begin{abstract}
Flow data were obtained using a tapered capillary, a chamfered capillary, and a uniformbore capillary in a McKee worker consistometer. With polyisobutene-cetane solutions, degradation occurred at lower rates of flow and persisted for a greater number of passes with flow entering the smaller end compared to flow entering the larger end of the tapered capillary. When degradation occurred in both directions at high rates of flow the pressure was larger for flow entering the larger end though after degradation ceased the pressure (used to overcome viscous resistance) was less for flow in this direction, compared to flow entering the smaller end in each case. Errors which might arise in the use of single pass instruments with nonuniform capillaries are pointed out.
\end{abstract}

\section{Introduction}

The development of the McKee worker-consistometer for investigating the effect of mechanical working on the rheological properties of lubricating greases, polymer solutions, and similar materials has been described in earlier publications $[1,2] .{ }^{1}$ With this apparatus the sample may be worked and its flow characteristics measured in the same series of operations. It has been used to degrade polymers in solution mechanically $[3,4]$.

The worker-consistometer consists essentially of two coaxial steel cylinders and mating pistons with a capillary shearing element in a disk between them. By means of the closely fitting pistons the material being tested is forced repeatedly through the shearing element, back and forth from one cylinder to the other. In recent work when measuring the force in both directions with capillary disks having drilled holes, it was observed that the higher force associated with shear degradation in the worker-consistometer persisted for more passes through the capillary in one direction than in the opposite direction. It was believed that this effect might be due to the geometry of the drilled holes of the capillary disks.

To investigate this effect three new capillary disks were constructed. One disk was made with as uniform a bore as could be constructed, another was made with a uniform bore chamfered at one end, and the third was made with a taper of the bore. This paper reports the results of this study.

\section{Apparatus}

With the worker-consistometer as formerly used, the measured force acting on the pistons included piston friction. From calibration data, corrections for piston friction could be applied for Newtonian fluids, but proper corrections could not be made for non-Newtonian samples. Samples containing volatile solvents could not be investigated because of the abnormally high piston friction resulting from evaporation of the solvent from the cylinder walls, and consequent formation of a polymer film on the cylinder walls. Therefore, a new worker-consistom.-

\footnotetext{
Figures in brackets indicate the literature references at the end of this paper.
}

eter unit was designed to permit measuring the pressure within the cylinders, thus avoiding errors resulting from piston friction, and to provide for minimizing evaporation of volatile solvents.

The cylinders and pistons of the new unit were made of hardened $440 \mathrm{C}$ stainless steel. Figure 1 shows the essential parts of the modified cam-operated instrument. The cam-operated driving mechanism [2] previously used was modified to operate the new unit in a horizontal position, to prevent spillage from the pressure ports during assembly. One cylinder has been set in the housing with the strain gage pressure pickup in place. The other cylinder, A, with accessories and strain gage pressure pickup, B, are left unassembled in front of the housing to show detail of design. The cylinders and push rods, C, were made longer than in the original units, and the push rods were fitted with Teflon seals, $\mathrm{D}$, to provide a closed vapor space at the outer end of each cylinder to minimize evaporation of volatile solvents from the cylinder walls. To further reduce evaporation, in using the new unit with volatile solvents, a drop of the solvent was placed in the outer end of each cylinder before the push rods were inserted.

Provision was made for connecting a small port, $\mathrm{E}$, near the inner end of each cylinder to fittings, F, provided with unbonded strain gage pressure pickups. A jelly made of glycerol, water, and gelatin was found to be preferable to liquid as a pressuretransmitting medium since it stayed in place in the pressure fitting and did not mix with benzene and similar solvents.

An indicating potentiometer for each strain gage was used so that readings from both gages could be observed at practically the same time to obtain the pressure difference in the cylinders. The strain gage pressure pickups were calibrated frequently with a dead weight gage tester.

Both the cam- and screw-operated instruments were used in obtaining measurements in this investigation. When working with solvents having relatively low volatility the pressures determined from the forces on the pistons were as accurate as the pressures measured directly on the modified camoperated instrument. Accordingly, much of the 


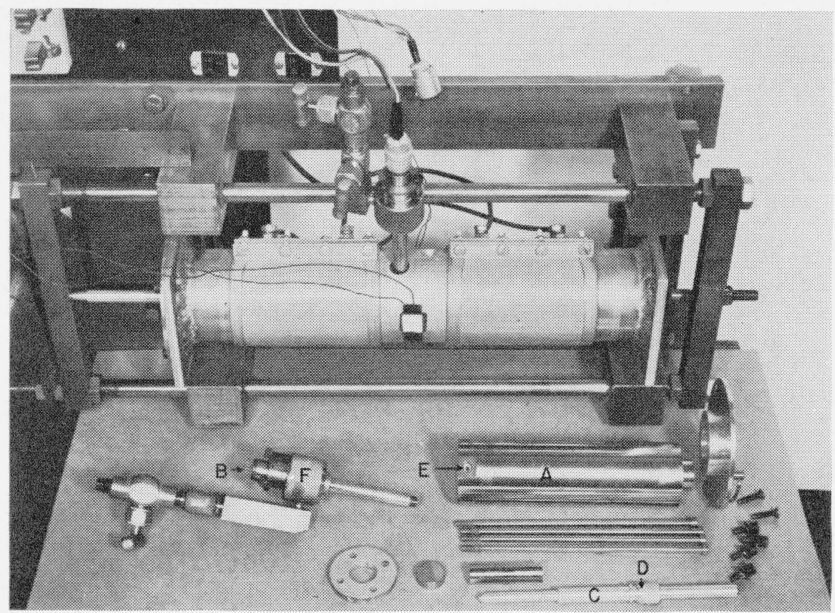

Figure 1. Modified parts of cam-operated McKee workerconsistometer.

data for the cetane-polyisobutene solution were obtained on the screw-operated instrument.

The new capillary disks were made with holes somewhat smaller than those used for most of the previous work, in order to extend the investigation to higher rates of shear. Disk No. 1044 (hole diameter $=0.01044$ in.) was made by soldering a piece of stainless steel capillary tubing in a stainless steel disk, grinding the ends to the desired length $(\mathrm{L}=$ $0.250 \mathrm{in}$.), and carefully removing the grinding burrs with a jeweler's reamer. This avoided the slight taper and roughness normally found in the drilled holes of previous capillary disks. Another disk, No. 1048 (hole diameter $=0.01048$ in.), was made in the same manner and then a $45^{\circ}$ chamfer was made at one end of the capillary, giving an entrance diameter of 0.0196 in. at the chamfered end. A third disk, No. 10-15, was made in the same way and was then reamed with a jeweler's tapered reamer so as to form a tapered hole, the hole being somewhat bellmouthed instead of having a straight taper because of the flexibility of the very small reamer. The diameters of the ends of the tapered capillary (measured with a microscope) were $0.0101 \mathrm{in}$. and 0.0148 in., and the effective diameter was $0.01100 \mathrm{in.}$ The effective diameters of the capillaries were determined by computation from flow measurements with NBS standard viscosity samples. These capillaries are shown diagrammatically (drawn to scale) in figures 2,3 , and 4 .

In Poiseuille's equation,

$$
Q=\frac{\pi a^{4} P}{8 \eta L}
$$

a correction [5] for conicality may be made by substituting

$$
\frac{3 a_{1}^{3} a_{2}^{3}}{a_{1}^{2}+a_{1} a_{2}+a_{2}^{2}}
$$

for $a^{4}$ (where $a_{1}$ and $a_{2}$ are the radii of the two ends of the capillary and $a$ is the radius of a uniform bore capillary). For disk No. 10-15 the mean diameter

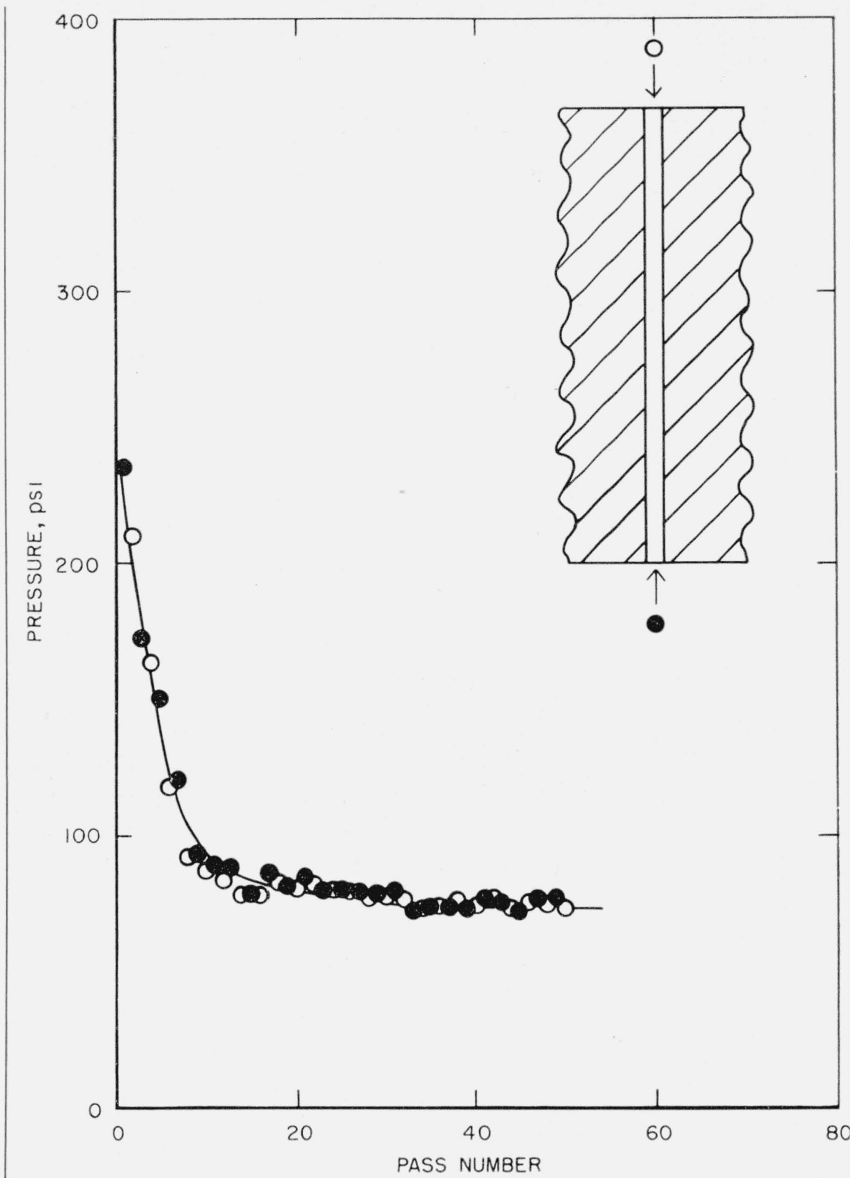

Figure 2. Pressure curve for 10 percent of polyisobutene in benzene worked through a uniform bore capillary at 56,000 reciprocal seconds rate of shear, at $30^{\circ} \mathrm{C}$.

See sketch of eapillary hole for directions of flow; bore, 0.01044 in.; length, $0.250 \mathrm{in}$.

computed from this expression is $0.0121 \mathrm{in}$. Since the hole in this disk is not truly conical because of the bell-mouth at the large end, this computed diameter is somewhat larger than the 0.011 in. effective diameter found by calibration. The effective diameter corresponds approximately to a straight-tapered hole $0.250 \mathrm{in}$. long with diameters of $0.010 \mathrm{in}$ and $0.0125 \mathrm{in}$. at the ends (1 percent taper).

An Ubbelohde suspended-level viscometer [6], in which the reservoir had been enlarged to serve as a mixing chamber, was used to determine reduced viscosities.

\section{Materials and Methods}

Most of the measurements were made on a 10percent (weight) solution of polyisobutene in cetane ( $n$-hexadecane). This polyisobutene is the unfractionated commercial Vistanex B-100 supplied by the Enjay Company. The solution was prepared by placing weighed quantities of polymer and solvent in glass jars and rolling the jars at about $6 \mathrm{rpm}$ until the solution appeared homogeneous on inspection. Previous experience [4] indicated that 2 weeks of rolling 


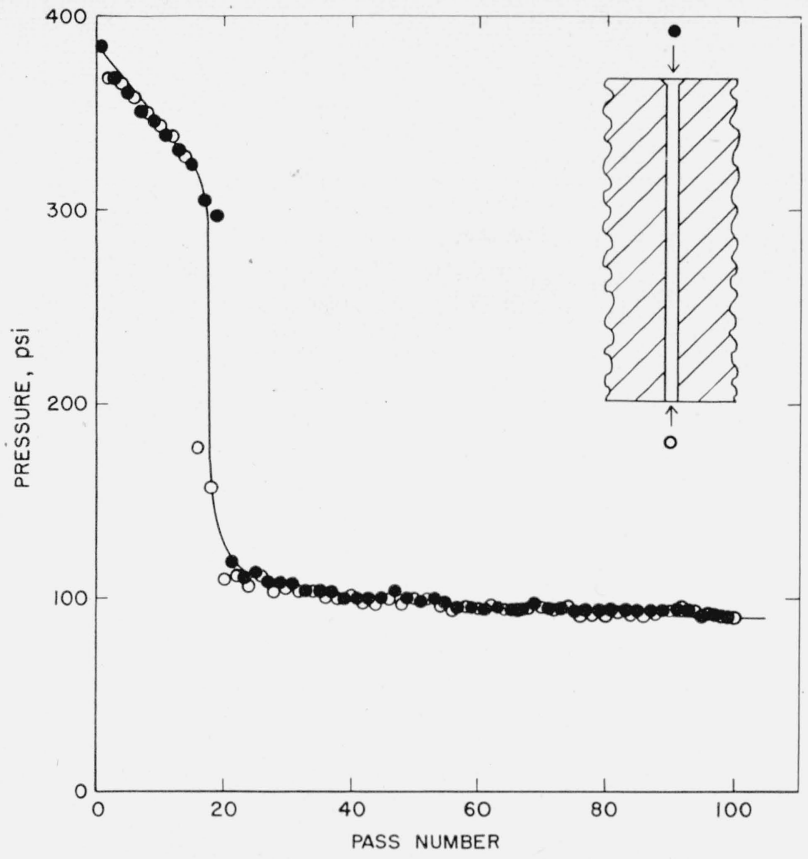

Figure 3. Pressure curve for 10 percent of polyisobutene in cetane worked through a chamfered capillary at 65,000 reciprocal seconds rate of shear, at $40^{\circ} \mathrm{C}$.

See sketch of chamfered capillary hole for directions of flow; bore, $0.01048 \mathrm{in}$; length, 0.250 in.; chamfer, to scale in sketch.

was ample for achieving complete solution. A 10percent solution of the same polyisobutene in benzene was also prepared.

For purposes of comparison a material which is Newtonian over the range of rates of shear investigated, and a non-Newtonian solution which does not degrade under the conditions of the investigation were included. The Newtonian material used was an NBS standard viscosity sample, No. $\mathrm{N}-24$. The non-Newtonian solution was a 10 -percent solution of polystyrene in toluene. The polystyrene was a high molecular weight sample (average molecular weight $\approx 2.0 \times 10^{6}$ ) supplied by the Dow Chemical Company. The solution was prepared in the same manner as the polyisobutene-cetane solution.

Measurements were made in the worker-consistometer on the polyisobutene-cetane system with each of the three capillary disks, the force or pressure required to move the sample through the capillary at a fixed rate being the measured variable. The number of passes for each run made with the tapered capillary varied from 8 to 100 in order to obtain samples at various stages of degradation for intrinsic viscosity determinations. One run of 530 passes was made to see if the difference in pressure in the two directions persisted after the main drop in pressure had occurred for both directions. Some runs were made with the sample entering the larger end of the tapered capillary on the initial pass, others were made with the sample entering the smaller end first. Similar measurements, but con-
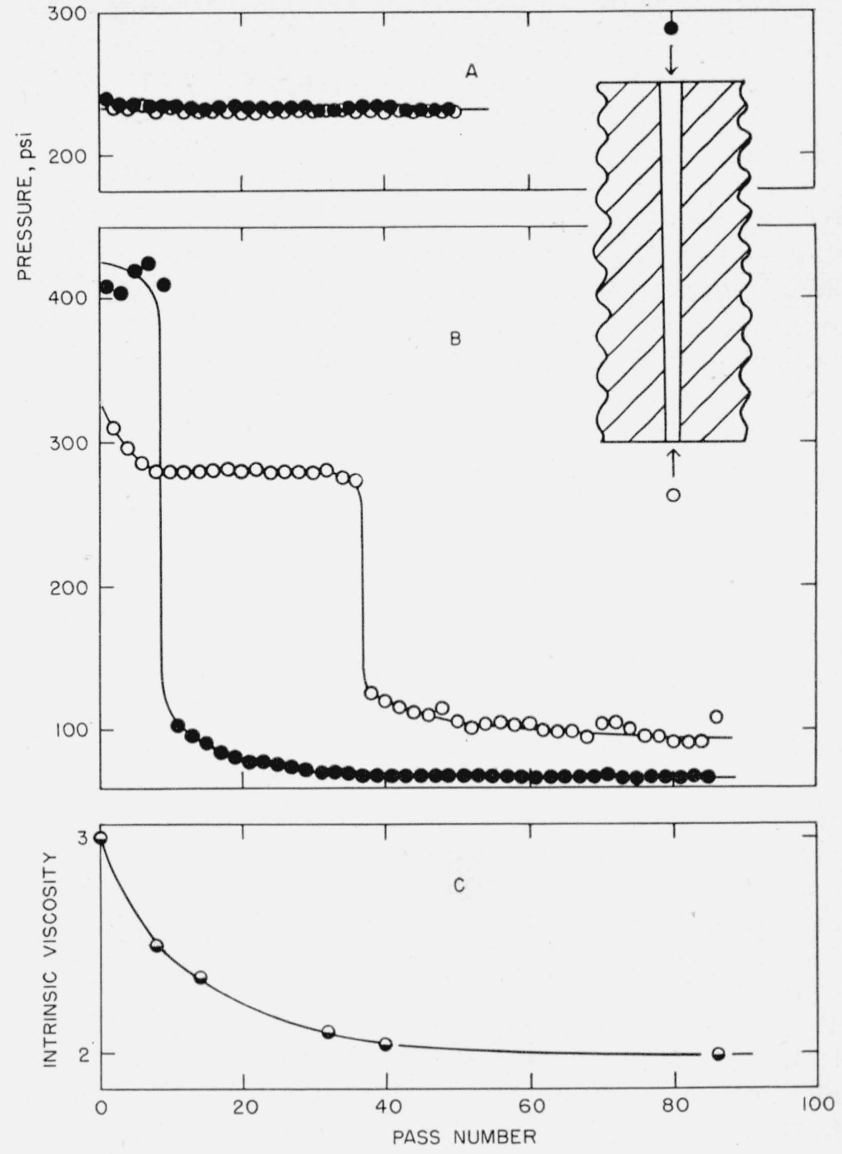

Figure 4A and 4B. Pressure curves for NBS standard viscosity sample oil $N-24(A)$ and 10 percent of polyisobutene in cetane $(B)$, worked through the tapered capillary at 56,000 reciprocal seconds rate of shear, at $40^{\circ} \mathrm{C}$.

See sketch of tapered capillary hole for diıections of flow; effective diameter 0.0110 in.; length, 0.250 in.; taper, to scale in sketch.

FIGURE 4C. Relation of intrinsic viscosity to number of passes worked through the tapered capillary at 56,000 reciprocal seconds rate of shear for 10 percent of polyisobutene in cetane.

siderably fewer of them, were made with polyisobutene in benzene, the polystyrene system, and with the $\mathrm{N}-24$ oil.

Dilute solutions were prepared from each of the worked samples from the worker-consistometer and from the unworked solutions. The intrinsic viscosities were determined for the dilute solutions $(1 / 2,1 / 4,1 / 8$, and $1 / 16 \%)$ by measuring flow time in the Ubbelohde viscometer, computing the reduced viscosities from the flow time and the viscometer constants, and extrapolating the reduced viscosities to zero concentration.

\section{Results}

Figure 2 shows a curve for a degradation run for polyisobutene in benzene using the uniform bore capillary. It was impossible to get such data with benzene or other highly volatile solvents prior to the 
modification of the cam instrument. Figure 3 shows a similar curve for the polyisobutene in cetane solution with the chamfered capillary disk. This same solution worked through the uniform bore capillary formed an almost identical curve. The curve for the Newtonian material worked through the tapered capillary is shown in figure 4A. In these figures the data are independent of the direction of flow. Figure $4 \mathrm{~B}$ shows the curves for nearly the same conditions as for figure 3 (the rate of shear varies with the capillary dimensions) but using the tapered capillary.

The intrinsic viscosity of the polyisobutene-cetane solution plotted against the number of passes is shown in figure $4 \mathrm{C}$. No further degradation as revealed by change in intrinsic viscosity occurred beyond the 86th pass, but some difference in pressures in the two directions persisted through 530 passes. A similar difference in pressures in the two directions occurred when the polystyrene solution was worked through the tapered capillary, although there was no indication of degradation.

Figure 5 shows a family of curves at different rates of shear (based on the mean diameter of 0.011 in.) for the polyisobutene-cetane system worked through the tapered capillary. At low rates of shear no observable degradation occurs. With increasing rate of shear, degradation occurs first with the sample entering the smaller end of the tapered capillary. With further increase in the rate of shear, degradation occurs when the sample enters the larger end of the capillary also. During degradation a large part of the observed pressure is used in breaking molecular bonds of the larger molecules [4]. When degradation occurs in both directions at relatively high rates of shear (above $24,000 \mathrm{sec}^{-1}$ in fig. 5) the pressure is larger for flow entering the larger end, though after degradation has ceased the pressure (used to overcome viscous resistance) is less for flow in this direction, compared to flow entering the smaller end of the capillary in each case. This indicates that the energy per pass used in degradation is larger for flow entering the larger end.

Special tests were made with 10-percent polyisobutene in cetane to ascertain if more degradation occurred for flow entering the larger end of the capillary compared to flow entering the smaller end. In these tests the driving gear train was changed for each pass so as to provide a rate of shear of 85,000 reciprocal seconds for flow in the direction being investigated and 3,400 reciprocal seconds for each return pass (no degradation occurs at 3,400 reciprocal seconds). Intrinsic viscosities were obtained with samples after 5 passes and after 10 passes entering the larger end at the high rate of shear and likewise after 5 and after 10 passes entering the smaller end. In each case the intrinsic viscosity for the sample entering the larger end was lower than for the sample entering the smaller end the same number of passes, which indicates more degradation per pass for flow entering the larger end under these conditions.

The apparent viscosity versus rate of shear

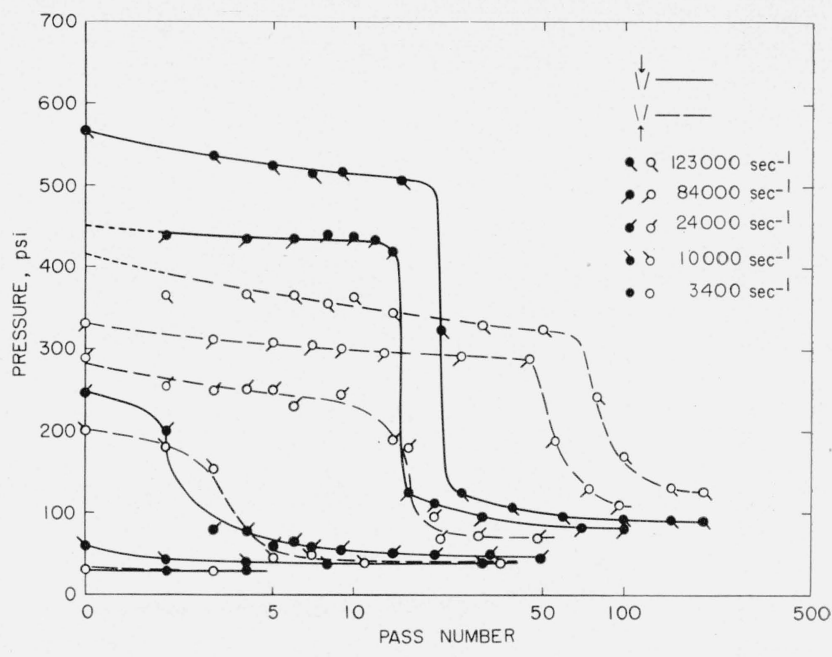

FIGURE 5. Family of typical pressure curves for 10 percent of polyisobutene in cetane, worked through the tapered capillary at $40^{\circ} \mathrm{C}$, at several rates of shear.

Plotted on semilogarithmic graph to accentuate plateaus before sudden drops in pressure.

(based on the 0.011 in. mean diameter) has been plotted in figure 6 for first pass values and for values after 530 passes at 56,000 reciprocal seconds. These data have been taken from the runs plotted in figure 5 and from additional similar runs. The difference in values in the two directions after 530 passes is not significant except at the higher rates of shear. The difference in first pass values in the two directions results from the fact that the pressures being measured are those of viscous flow combined with those necessary to bring about degradation. For this particular material (10 percent polyisobutene in cetane) the difference in values in the two directions at 3,000 reciprocal seconds is slight, but at 10,000 reciprocal seconds the value for the direction in which the sample enters the smaller end of the capillary is about 225-percent higher than for the direction in which the sample enters the larger end. Then at about 27,000 reciprocal seconds there is no difference in values in the two directions, but at 100,000 reciprocal seconds there is again a difference in values of about 34 percent with the directions reversed. Where viscosity measurements are made on this kind of material in single-pass capillary viscometers, a slight taper in the capillary may make great differences in the values obtained in comparison with capillaries having no taper or having taper in the opposite direction.

\section{Discussion}

The objective of this work with special capillaries was to investigate the effects encountered with flow of non-Newtonian materials which undergo shear degradation through capillaries having slight tapers or slight defects (unrecognized) at one edge, by using capillaries with somewhat exaggerated cases of these departures from uniform bore. The results indicate that a slight taper may have a large effect on the flow 
characteristics, but that a slight chamfer at the edge of the hole has no significant effect.

The equation for flow of a Newtonian material through a tapered capillary can be solved, ignoring end effects, and predicts the relation between pressure drop and quantity of flow as given by Barr [5]. This equation indicates that the pressure drop is independent of the direction of flow, and this was confirmed with tests with Newtonian oils. The analysis of the flow of a non-Newtonian fluid in a tapered capillary has not been made, nor have the end effects been analyzed mathematically.

For a non-Newtonian fluid, when no degradation is occurring it appears that the orientation and alinement of the polymer molecules require less pressure at a given rate of flow when entering the larger end of the tapered capillary than when entering the smaller end.

For given rates of flow the rate of shear at the smaller end is greater than at the larger end of the capillary. At high rates of flow a large proportion of the pressure drop probably occurs in the capillary near each entrance end. This could explain why degradation occurs at lower rates of flow and persists for a greater number of passes with flow entering the smaller end compared to flow entering the larger end of the capillary. When the rate of flow (and rate of shear at the larger end) is large enough to cause degradation with flow entering the larger end the pressure associated with the degradation is abnormally high compared to the pressure for flow in the opposite direction; this and the fact that the degradation per pass is larger for flow entering the larger end may be associated with the larger cross-sectional area of the larger end.

In figure 6 , the effective capillary diameter $(0.011$ in.) obtained with Newtonian oils was used for computing the rate of shear and the apparent viscosity values. If we assume diameters of 0.01055 in. and $0.0129 \mathrm{in}$. (averages of $0.011 \mathrm{in}$. and the respective end dimaters) and compute the values of rate of shear and apparent viscosity for the first pass data in figure 6 accordingly, the curves nearly coincide in the range of rates of shear from 2,000 to 15,000 reciprocal seconds; but at higher rates of shear the apparent viscosity for flow entering the larger end becomes increasingly higher than for flow entering the smaller end at given rates of shear (although in both cases the apparent viscosity is decreasing with increase in rate of shear).

In these flow experiments the Reynolds numbers were far below the value of 2,000 frequently considered as a criterion for the onset of perceptible turbulence with Newtonian fluids in capillaries. For the data presented in figure 6 , if we consider the apparent viscosity as ranging from 5 down to 1 poise for rates of shear ranging from 7,000 to 121,000 reciprocal seconds, respectively (not counting the energy used in degradation) then the Reynolds numbers range from 0.5 to 45 , computed from the mean diameter of 0.011 in. With polyisobutene

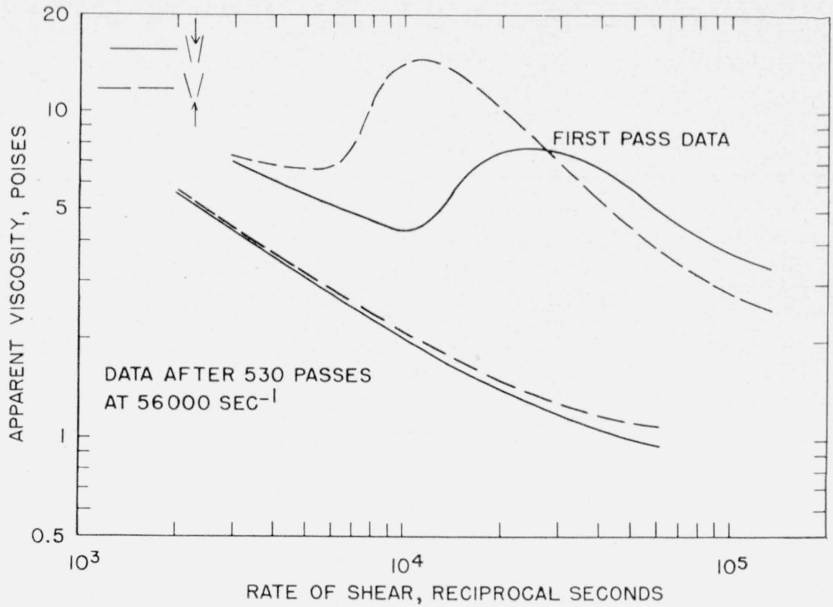

Figure 6. Apparent viscosity versus rate of shear for 10 percent of polyisobutene in cetane, with the tapered capillary, at $40^{\circ} \mathrm{C}$ for new (unworked) samples and for a worked sample.

solutions Schnurman [7] has obtained data which he believes indicate turbulence beginning at a Reynolds number of about 10 . In figure 6 the curve for the sample which had been degraded by working 530 passes indicates that there is no turbulence under these conditions. The abnormally high values of apparent viscosity for the first pass data are the result of including the forces used in degradation; and, although rupturing of large molecules may disturb the flow pattern, it is not believed that the flow is turbulent in the sense that this term is applied to flow with Newtonian fluids.

The authors are grateful for consultations with A. B. Bestul, R. S. Marvin, E. A. Kearsley, J. F. Swindells, C. M. Tchen, and L. A. Wall.

\section{References}

[1] S. A. McKee and H. S. White, A worker-consistometer for lubricating greases, ASTM Bul. 153, 90 (August 1948).

[2] S. A. McKee and H. S. White, The McKee workerconsistometer with constant speed drives, J. Research NBS 46, 18 (1951) RP2170.

[3] A. B. Bestul and H. V. Belcher, Degradation of polyisobutenes on shearing in solution, J. Appl. Phys. 24, 1069 (1953).

[4] A. B. Bestul, Composition of apparent shearing forces during shear degradation of polymers, J. Appl. Phys. 25, 1011 (1954).

[5] G. Barr, A monograph of viscosity, p. 64 (Oxford University Press, London, 1931).

[6] J. Ubbelohde, J. Inst. Petrol. Tech. 19, 376 (1933).

[7] Quoted by Frisch and Simha in: F. R. Eirich, Rheology, theory and applications, 1, 607 (Academic Press, Inc., New York, N. Y., 1956).

Washington, August 19, 1957. 